\title{
Análise das práticas de sustentabilidade utilizadas na gestão da cadeia de suprimentos: pesquisa de campo no setor automotivo brasileiro
}

\section{Analysis of sustainability practices used in supply chain management: a field research in the Brazilian automotive sector}

\author{
Rosangela Maria Vanalle ${ }^{1}$ \\ Leandro Blanco dos Santos ${ }^{1}$
}

\begin{abstract}
Resumo: O desequilíbrio ambiental decorrente de ações do homem sobre o meio ambiente obrigou os principais governos do mundo a incluir questões ambientais nas suas reuniões. Este desequilíbrio é consequência do consumo descontrolado dos recursos naturais e da geração de resíduos e emissões atmosféricas que se intensificaram desde a revolução industrial. Este estudo tem como objetivo identificar e analisar as práticas mais valorizadas de sustentabilidade, os fatores relacionados ao desempenho ambiental, financeiro e operacional considerados no processo de seleção e desenvolvimento de fornecedores de empresas integrantes de cadeias de suprimentos no setor automotivo brasileiro. O setor automotivo foi escolhido pelo fato de ter sido referência com relação às práticas de qualidade e pelo fato de possuir grande influência entre as empresas participantes de sua cadeia de suprimentos, facilitando, assim, a disseminação de práticas sustentáveis. O método utilizado foi uma revisão bibliográfica sobre o assunto e uma pesquisa de campo exploratório-descritiva. $\mathrm{O}$ instrumento para coleta de dados das empresas foi um questionário, utilizando uma escala de Likert de 5 pontos. Os dados foram tratados por meio de estatística descritiva, coeficientes alfa de Cronbach e testes de hipóteses. Como resultado, foram identificadas as práticas de sustentabilidade mais valorizadas e os fatores considerados no processo de seleção e desenvolvimento de fornecedores pelas empresas. Os resultados obtidos servem como base de direcionamento para novos estudos sobre o assunto e contribuem com a literatura sobre o tema.
\end{abstract}

Palavras-chave: Sustentabilidade. Práticas sustentáveis. Cadeia de suprimentos. Indústria automotiva.

\begin{abstract}
The environmental imbalance caused by human actions has forced the major world governments to include environmental issues in their agendas. This imbalance is a consequence of the uncontrolled consumption of natural resources and the generation of waste and emissions that have intensified since the industrial revolution. This study aims to identify and analyze the most valued practices of sustainability, factors related to environmental, financial and operational performance considered in the process of selecting and developing suppliers of companies from supply chains in the Brazilian automotive sector. The automotive sector was chosen because it is considered a reference in relation to quality practices and also because it has great influence on the companies which participate in its supply chain, thus facilitating the dissemination of sustainable practices. A literature review on the subject and an exploratory-descriptive field research were used as the study methodology. A survey of companies was utilized as instrument for data collection, using a Likert scale of 5 points. The data were treated by descriptive statistics, Cronbach alpha coefficients, and hypothesis testing. As a result, the most valued sustainability practices and the factors considered in the process of selection and development of suppliers by companies were identified. The results serve as a basis for targeting new studies and contribute to the literature on the theme.
\end{abstract}

Keywords: Sustainability. Sustainable practices. Supply chain. Automotive industry.

\section{Introdução}

O homem, desde a Revolução Industrial, tem degradado o meio ambiente, pelo consumo descontrolado dos recursos naturais por parte das indústrias de manufatura e por meio da emissão de poluentes nas suas mais diversas formas (ZUCATTO, 2008).
No final da década de 1980, as pessoas começaram a se reunir insatisfeitas com a maneira como as empresas vinham tratando o meio ambiente em sua incessante exploração de recursos para produzir e conquistar mercados (CAIRNCROSS, 1992 apud POLIDÓRIO, 2009).

\footnotetext{
Programa de Pós-graduação em Engenharia de Produção, Universidade Nove de Julho - UNINOVE, CEP 05001-100, São Paulo, SP, Brasil, e-mail: rvanalle@uninove.br; leandro.blanco@uninove.edu.br
} 
Segundo Linton, Klassen e Jayaraman (2007), da mesma forma que ocorreu com a questão da norma ISO 9001, que se tornou um padrão mundial de certificação de sistemas de gestão da qualidade, a ênfase que a União Europeia tem dado à sustentabilidade pode ser um prenúncio para a criação de outras normas que podem vir a se tornar mundiais. A União Europeia incluiu o tema sustentabilidade em sua legislação e criou algumas diretivas como a Diretiva RoHS (Restriction of Hazardous Substances in Electrical and Electronic Equipment), que restringe o uso de substâncias perigosas em equipamentos elétricos e eletrônicos e a Diretiva WEEE (Waste Electrical and Electronic Equipment), que trata dos resíduos de equipamentos elétricos e eletrônicos.

Regulamentações são necessárias para criar pressões que motivem as empresas a inovar, melhorar a qualidade ambiental, alertar e educar as empresas a respeito de prováveis ineficiências de recursos e potenciais áreas para inovações tecnológicas (PORTER; LINDE, 1995).

Além do cumprimento da legislação, as empresas devem evitar causar danos ao meio ambiente e/ ou à sociedade, pois problemas ambientais e sociais podem causar danos à imagem das empresas perante a sociedade e o mercado em que atuam e, consequentemente, afetar suas vendas (SEURING et al., 2008).

Segundo Paula, Gonçalves e Coscarelli (2008), os investidores passaram a buscar empresas que executem atividades sustentáveis em suas plantas, pois estas empresas estão mais capacitadas a lidar com riscos econômicos, ambientais e sociais, portanto estão mais propícias a gerar maiores resultados.

Os desafios ambientais não se limitam aos portões das empresas, mesmo porque muitas operam em nível mundial e na busca de alternativas econômicas para sua manufatura terceirizam parte de seus processos produtivos, contratando de outras empresas a extração de matérias-primas, a manufatura e a distribuição de produtos, sejam eles acabados ou insumos para outros processos (NAWROCKA; BRORSON; LINDHQVIST, 2009).

Por meio de requisitos de fornecimento é possível incluir práticas sustentáveis ao longo da cadeia de suprimentos, como a eliminação ou restrição do uso de matérias-primas perigosas, conforme citado por Hsu e Hu (2009) ou por meio de outras exigências, como a verificação do desempenho ambiental, práticas de controle da poluição e obtenção de certificações ambientais, conforme citado por Bai e Sarkis (2010a).

A escolha pela indústria automotiva para a realização deste estudo se deu por estar entre as maiores indústrias do mundo; no Brasil, responde por quase $25 \%$ do Produto Interno Bruto (PIB) do setor industrial e 5\% do PIB total, com faturamento acima de US $\$ 100$ bilhões (ASSOCIAÇÃO..., 2014). Seus sistemas de gestão e suas práticas de organização, adotadas em resposta às pressões ambientais, podem servir de modelo para empresas de outros setores e pelo fato de que as montadoras exercem grande influência sobre os componentes de sua cadeia de suprimentos, por serem o elo mais forte e definirem os requisitos para fornecimento.

Esta indústria possui um elevado número de fornecedores com diferentes tipos de processos produtivos; que podem causar diversos impactos ao meio ambiente e por possuir empresas com grande poder econômico e político na cadeia de suprimentos em que está inserida. Assim sendo, as empresas compradoras deste setor têm poder para influenciar e têm a responsabilidade de disseminar os conceitos de sustentabilidade em suas cadeias de suprimentos (FAUSTINI; ALVES, 2009).

Além de gerenciar os impactos ambientais da sua manufatura, as organizações devem atentar para os impactos ambientais decorrentes dos processos de manufatura dos integrantes da sua cadeia de suprimentos. Portanto, é importante que selecionem e monitorem seus fornecedores de maneira criteriosa, reduzindo, desta forma, os problemas causados por seus fornecedores que possam denegrir sua imagem perante o mercado em que atuam e perante a sociedade.

De acordo com Seman et al. (2012), a gestão da cadeia de suprimentos verde (GCSV) tem sido um tema importante para os pesquisadores. No entanto, ainda é limitado o número de estudos que investigam a adoção e implementação da GCSV nos países em desenvolvimento.

A GCSV tem como pressuposto que as empresas não agem sozinhas, mas sim se interligando, desde fornecedores de matéria-prima até os consumidores finais, formando as chamadas cadeias de suprimentos, que devem estar preocupadas em atender às exigências do mercado com a adoção de princípios de gestão ambiental (JABBOUR et al., 2013).

Esta pesquisa busca o preenchimento da lacuna existente na literatura acadêmica por meio de uma pesquisa com o objetivo de identificar e analisar as práticas de sustentabilidade ambientais que estão sendo requisitadas e valorizadas por empresas integrantes da cadeia de suprimentos do setor automotivo; levantar as práticas e os fatores relacionados ao desempenho ambiental, financeiro e operacional considerados no processo de seleção e desenvolvimento de fornecedores por empresas integrantes de cadeias de suprimentos no setor automotivo brasileiro.

Espera-se também contribuir com os profissionais da indústria automobilística e de outras indústrias que buscam tornar suas empresas mais sustentáveis oferecendo um referencial que as ajude na avaliação de suas práticas.

Quanto à estrutura do artigo, a Seção 2 consiste em uma revisão bibliográfica que contempla aspectos 
relacionados à Cadeia de suprimentos; Cadeia de suprimentos sustentável; Processo de seleção e desenvolvimento de fornecedores; Processo de seleção e desenvolvimento de fornecedores sustentáveis; e Exemplos de práticas sustentáveis aplicadas por empresas do setor automotivo. Em seguida, a Seção 3 descreve os procedimentos de pesquisa utilizados neste estudo e a Seção 4 apresenta e discute os resultados desta pesquisa. Por fim, a Seção 5 apresenta algumas considerações finais.

\section{Revisão da literatura}

Neste item, é feita uma revisão bibliográfica, na qual são abordados os seguintes assuntos: cadeia de suprimentos; cadeia de suprimentos sustentável (verde); o processo de seleção e desenvolvimento de fornecedores; o processo de seleção e desenvolvimento de fornecedores sustentáveis; e exemplos de práticas sustentáveis aplicadas por empresas do setor automotivo.

\subsection{Cadeia de suprimentos}

Scavarda e Hamacher (2001) definem a cadeia de suprimentos como sendo a rede formada por todas as empresas envolvidas na fabricação e comercialização de um produto ou serviço que será entregue a um cliente final.

A cadeia de suprimentos é a rede de serviços, materiais e fluxos de informação que une os processos de relacionamento com clientes, de atendimento a pedidos e de relacionamento com fornecedores e clientes. Sua administração deve desenvolver uma estratégia para organizar, controlar e determinar os recursos envolvidos no fluxo de serviços e materiais no interior da cadeia de suprimentos (KRAJEWSKI; RITSMAN; MALHORTA, 2009; LAMBERT; COOPER; PAGH, 1998).

A visão de supply chain tem como principais objetivos: reduzir custos de fornecimento; reduzir o tempo total; aumentar as margens dos produtos; aumentar a produção e melhorar o retorno de investimentos (MARTINS; LAUGENI, 2006).

Para o Council of Supply Chain Management Professionals (2010), a gestão da cadeia de suprimentos, em sua essência, integra a gestão de oferta e demanda dentro e entre as organizações. Para tanto, é necessário planejar e gerenciar todas as atividades que fazem parte do fornecimento, aquisição, conservação e movimentação logística, além de coordenar e colaborar com os fornecedores, prestadores de serviços terceirizados e clientes, criando assim um elo de parceria entre os integrantes da cadeia.

Os grandes fabricantes de veículos (montadoras) possuem poderosas forças para a criação de suas cadeias de suprimentos e influências sob muitos outros negócios, sendo que a maioria obviamente surge com relação aos seus fornecedores de materiais e componentes, que podem constituir até $80 \%$ do valor de um veículo acabado. Assim sendo, o departamento de compras dos fabricantes de veículos está entre os mais profissionais e maiores sistemas no mundo, sendo particularmente adepto de obter reduções de custos de seus fornecedores (ORSATO; WELLS, 2007).

\subsection{Cadeia de suprimentos sustentável (verde)}

Sustentabilidade é comumente definida como a utilização dos recursos para atender às necessidades do presente sem comprometer a capacidade das gerações futuras de atenderem a suas próprias necessidades (LINTON; KLASSEN; JAYARAMAN, 2007).

Leite, Silva e Menezes (2009) utiliza o conceito da busca pelo desenvolvimento economicamente viável, socialmente justo e ambientalmente correto para descrever o desenvolvimento sustentável.

Srivastava (2007) define o termo gestão sustentável da cadeia de suprimentos (Sustainable Supply Chain Management ou Green Supply Chain Management (GSCM)) como a integração do pensamento ambiental na cadeia de suprimentos, incluindo o projeto do produto, a seleção das matérias-primas e suas fontes, os processos de manufatura, a entrega do produto aos consumidores, como também o fim da vida útil deste produto, incluindo a gestão do produto após sua vida útil, ou seja, a logística reversa do produto.

Uma empresa pode escolher se envolver diretamente e investir seus próprios recursos para melhorar as práticas ambientais dos membros da cadeia, ou pode usar seu poder ou mecanismos do mercado para influenciá-las (VACHON; KLASSEN, 2006).

A cadeia de suprimentos verde inclui atividades de redução de perdas; reciclagem; desenvolvimento de fornecedores; desempenho dos compradores; compartilhamento de recompensas e riscos; adoção de tecnologias "limpas"; adequações à legislação; reutilização de materiais; economia de água e energia; utilização de insumos ecologicamente corretos; processos de produção enxutos e flexíveis; comprometimento e conscientização ambiental dos participantes da cadeia (BOWEN et al., 2001).

De acordo com Pusavec, Krajnik e Kopac (2010), a indústria vem dedicando esforços a favor da sustentabilidade por meio de mudanças no projeto de seus produtos, desenvolvimento de novos materiais, reuso e reciclagem de materiais e redução de desperdícios, existindo uma prospecção de aumento de interesse dos investidores por indústrias com práticas de sustentabilidade e a aplicação do conceito de 6Rs (remanufaturar; reprojetar; recuperar; reciclar; reutilizar; e reduzir) como a evolução da produção verde e base da produção sustentável. Neste estudo, são citadas algumas formas de melhorar a 
sustentabilidade do ponto de vista da produção, tais como: reduzir o consumo de energia dos processos; reduzir o desperdício (gerar menos resíduos, aumentar o reuso e a reciclagem de resíduos); utilizar os recursos de forma eficiente; utilizar materiais recicláveis ou reutilizáveis; adotar métodos de avaliação do ciclo de vida.

As vantagens de iniciativas sustentáveis nas cadeias de suprimentos estão intrinsecamente relacionadas com a criação de valor de negócio real e sustentável. Segundo Pagell e Zhaohui (2009) a busca pela sustentabilidade pode contribuir para reexaminar os processos, materiais e conceitos operacionais e de apoio à inovação, o que consequentemente resultará em aumento da produtividade. Sendo assim, as corporações mais sustentáveis têm melhores chances de competir e permanecer no mercado a longo prazo do que empresas tradicionais.

De acordo com Santa-Eulalia et al. (2010), com o intuito de melhorar seus desempenhos econômico, social e ambiental, as organizações devem desenvolver um relacionamento colaborativo e harmonioso entre os componentes da cadeia de suprimentos em que operam, assim sendo, os relacionamentos entre empresas tornaram-se um fator determinante para a competitividade e sustentabilidade, portanto devem ser incluídas práticas de sustentabilidade (econômico, social e ambiental) no processo de seleção de fornecedores, buscando parcerias com empresas que tenham comportamentos semelhantes com relação à sustentabilidade.

As empresas têm implantado práticas de gestão da cadeia de suprimentos verde (GCSV) em resposta à demanda dos clientes por produtos e serviços que sejam ambientalmente sustentáveis e em resposta às regulamentações ambientais governamentais. Estas práticas exigem que os fabricantes trabalhem em conjunto com fornecedores e clientes para aumentar a sustentabilidade ambiental (GREEN JUNIOR et al., 2012).

\subsection{Processo de seleção e desenvolvimento de fornecedores}

O processo de selecionar e avaliar fornecedores possui um papel fundamental para uma empresa; logo, deve ser realizado de forma a obter os melhores resultados. Este processo é considerado o ponto inicial da relação entre a empresa "cliente" e o fornecedor (ROSA, 2004).

Em pesquisa realizada por Jabbour e Jabbour (2009), as empresas possuem fornecedores trabalhando em conjunto com suas atividades de desenvolvimento de produtos e produção de peças ou subconjuntos, sendo que a produção pode ser realizada dentro da empresa contratante (consórcio modular) ou na empresa contratada (JABBOUR; JABBOUR, 2009).
Segundo Silva (2004), para se desenvolver uma cadeia de suprimentos altamente competente, necessita-se que os objetivos particulares sejam transformados em objetivos mútuos, buscando, desta forma, melhorias compensadoras para todos os integrantes da cadeia de suprimentos.

A competitividade de uma empresa está fortemente ligada à sua rede de fornecedores, portanto a empresa deve ter como um dos objetivos da sua estratégia, manter uma rede de fornecedores altamente capacitados a atender seus requisitos (FREJ et al., 2009).

Veloso (2000), por sua vez, estudou o processo de seleção de fornecedores na cadeia de suprimentos da indústria automotiva, que, além dos critérios de qualidade, preço e estrutura de custos, velocidade e confiabilidade na entrega, capacidade tecnológica e comprometimento, inclui no seu processo de seleção de fornecedores os seguintes critérios: capacidade em pesquisa e desenvolvimento de produtos e processos; flexibilidade de volume de produção, produtos e processos; capacidade técnica da mão de obra e estabilidade financeira.

Handfield e Nichols (2004) citam que os critérios mais comuns utilizados no processo de seleção tradicional de fornecedores pelas organizações são: qualidade, preço, velocidade e confiabilidade na entrega, capacidade tecnológica, estrutura de custos e comprometimento.

Os principais critérios adotados, de acordo com Chang e Hung (2010) no processo de seleção de fornecedores são:

- Qualidade (avalia a qualidade do produto fornecido);

- Custo (avalia o custo investido pela empresa na compra do produto);

- Desempenho na entrega (avalia a pontualidade na entrega pelo fornecedor);

- Serviço (avalia o serviço de pós-venda e apoio prestado pelo fornecedor);

- Flexibilidade (avalia a capacidade do fornecedor para apoiar o plano de mudança de produção da empresa).

De acordo com Jabbour e Jabour (2009), os fornecedores têm desempenhado papéis estratégicos para as organizações, pois são vitais na criação de uma vantagem competitiva e suas ações têm impacto positivo sobre o desempenho da organização. São importantes porque se tornam responsáveis pelas peças e subsistemas do produto final, que incorporam os custos de produção, desenvolvimento tecnológico e de desempenho em qualidade, portanto devem ser selecionados de acordo com os fatores operacionais e estratégicos da organização.

Zhu, Sarkis e Lai (2013), utilizando uma amostra de 396 fabricantes chineses, mostram que as pressões institucionais têm impulsionado os fabricantes a 
adotarem práticas internas e externas de GCSV e que essas práticas não afetam diretamente o desempenho econômico, mas podem melhorá-lo indiretamente.

\subsection{Processo de seleção e desenvolvimento de fornecedores sustentáveis}

O processo de seleção de fornecedores pode ser utilizado para estabelecer e transferir, aos integrantes a montante na cadeia de suprimentos, critérios de sustentabilidade. Este processo é identificado pela literatura como um processo principal e estratégico para a disseminação da sustentabilidade na cadeia de suprimentos (FAUSTINI; ALVES, 2009).

O gerenciamento estratégico dos relacionamentos entre empresas passou a ser visto como fator determinante para a competitividade e sustentabilidade, e tornou-se uma das melhores maneiras para gerir as organizações, contemporaneamente, pois, em um ambiente em que o mercado é cada vez mais dinâmico e turbulento, a habilidade das empresas em desenvolver e controlar com sucesso seus relacionamentos com outras empresas emerge como uma forte vantagem competitiva (BATT; PURCHASE, 2004).

Para categorizar os programas de seleção de fornecedores, pode-se utilizar como base inicial as práticas de sustentabilidade da cadeia de suprimentos. Estas práticas são classificadas como avaliativas ou colaborativas. Nas práticas avaliativas, diversos fatores podem ser avaliados, por exemplo, o desempenho ambiental da organização que está sendo avaliada; já nas práticas colaborativas, existe uma assistência entre as empresas (BAI; SARKIS, 2010a).

Bai e Sarkis (2010a) citam, numa perspectiva sustentável e de forma resumida, algumas práticas ambientais e suas respectivas métricas, que podem ser utilizadas como base no processo de seleção de fornecedores (Quadro 1). As práticas ambientais de sustentabilidade referem-se aos controles operacionais implantados para controlar os aspectos ambientais das atividades realizadas pelas empresas, à prevenção da poluição, que pode ser realizada por meio de melhorias no projeto do produto e do processo e uma das práticas mais comuns dentre as empresas com preocupação ambiental é a implantação de um sistema de gestão ambiental, o que obriga a empresa a definir, além de uma política com objetivos ambientais, a identificar, tratar e monitorar os aspectos ambientais significativos consequentes de suas atividades. Por outro lado o desempenho ambiental faz referência ao consumo de recursos naturais, como matérias-primas, energia elétrica, combustíveis fósseis, água e a geração de elementos poluentes pelos processos da empresa e que podem ou não ser reutilizados ou reciclados pela própria empresa em sua linha de produção.

Segundo Carter e Jennings (2000), os principais critérios de sustentabilidade utilizados na seleção de fornecedores e decisão de compra são:

- estabelecimento de lista de controle de substâncias perigosas;

- preferência por matérias-primas que não contenham substâncias proibidas;

- avaliação de plataformas para avaliação ambiental de fornecedores;

- dados de produtos verdes aprovados;

- mecanismos de auditoria de gestão ambiental.

Relações entre empresas são fundamentais para a boa coordenação das cadeias de suprimentos e de melhorias no desempenho das capacidades produtivas dos fornecedores (LAMMING, 1996;

Quadro 1. Métricas ambientais para decisão na seleção de fornecedores.

\begin{tabular}{|c|c|c|}
\hline Categorias & Fatores & Subfatores \\
\hline \multirow{9}{*}{ Práticas Ambientais } & \multirow{2}{*}{ Controles da Poluição } & Remediação \\
\hline & & Controles no fim do processo \\
\hline & \multirow{2}{*}{ Prevenção da Poluição } & Adaptação de produto \\
\hline & & Adaptação de processo \\
\hline & \multirow{5}{*}{ Sistema de Gestão Ambiental } & Estabelecimento de Compromisso e Política Ambiental \\
\hline & & Identificação dos aspectos ambientais \\
\hline & & Planejamento dos objetivos ambientais \\
\hline & & Atribuição de responsabilidade ambiental \\
\hline & & Verificação e avaliação das atividades ambientais \\
\hline \multirow{6}{*}{ Desempenho Ambiental } & \multirow{3}{*}{ Consumo de recursos } & Consumo de energia \\
\hline & & Consumo de matérias-primas \\
\hline & & Consumo de água \\
\hline & \multirow{3}{*}{ Produção de poluentes } & Produção de agentes poluidores \\
\hline & & Produção de produtos tóxicos \\
\hline & & Produção de resíduos \\
\hline
\end{tabular}

Fonte: Adaptado de Bai e Sarkis (2010a). 
HANDFIELD et al., 2000; SCANNELL; VICKEY; DROGE, 2000). A relação no fornecimento é um importante canal para comunicar os requisitos do cliente aos fornecedores e atingir metas de longo prazo da produção (LAMMING, 1996; HANDFIELD et al., 2000; SCANNELL; VICKEY; DROGE, 2000). As relações na cadeia de suprimento, muitas vezes, podem obter melhorias do desempenho e da vantagem competitiva superior que não são facilmente geradas pelas transações de mercado aberto (BURT; DOYLE, 1993; DYER; NOBEOKA, 2000).

Pode-se dizer que o processo de desenvolvimento de fornecedores é algo dinâmico, pois atua numa complexa rede de relações intra e interempresas, além do que em muitos casos, algumas etapas se sobrepõem.

A atividade de desenvolvimento de fornecedores consiste na prestação de serviços de consultoria e de assessoria, por parte das empresas compradoras a seus fornecedores. Estas atividades também influenciam os aspectos culturais presentes no contexto industrial das empresas e têm como principal objetivo auxiliar as empresas fornecedoras a identificar e analisar problemas relacionados não somente a métodos e processos de fabricação, mas também a práticas organizacionais administrativas e políticas empresarias (RAZZOLINI; RODRIGUEZ, 2004).

Dado o grande número de práticas para o desenvolvimento de fornecedores sustentáveis que as empresas podem adotar, é plausível citar que nem todas as empresas podem adotar todas as práticas, visto que empresas com recursos limitados deverão escolher quais práticas para seleção de fornecedores sustentáveis deverão colocar em prática. Não existem estudos que tratam a priorização destas práticas pelas empresas, a maioria dos estudos trata do relacionamento entre os membros da cadeia de suprimentos (BAI; SARKIS, 2010b).

Por meio de uma perspectiva estratégica, Silva (2004) cita que as atividades de desenvolvimento de fornecedores podem contribuir para o estreitamento das relações entre as empresas compradoras e as empresas fornecedoras, de modo a consolidar a parceria

Muitos estudos procuram associar as práticas de desenvolvimento de fornecedores sustentáveis com o desempenho econômico e ambiental das empresas, contudo na literatura estas práticas não necessariamente se relacionam a atividades de desenvolvimento de fornecedores, mas podem ser aplicadas para tornar a cadeia de suprimentos mais sustentável. Por exemplo, a prática de realizar auditorias ambientais em fornecedores só pode ser utilizada para efeito de seleção de fornecedores e não necessariamente para auxiliar no desenvolvimento de fornecedores (BAI; SARKIS, 2010b).

\subsection{Exemplos de práticas sustentáveis aplicadas por empresas do setor automotivo}

Este tópico da pesquisa apresenta as práticas de sustentabilidade que estão sendo aplicadas na cadeia de suprimentos da indústria automotiva mundial para seleção e desenvolvimento de seus fornecedores, objetivando a melhoria contínua ambiental e social de todos os integrantes desta rede.

Zhu, Sarkis e Lai (2007) realizaram uma survey junto aos fornecedores da cadeia de suprimentos da fabricante de motores chinesa Dalian Diesel Engine Plant (DDEP), a qual trata de pressões, práticas e desempenho por meio do gerenciamento sustentável da cadeia de suprimentos da indústria automotiva chinesa. Neste estudo, eles identificaram as seguintes práticas:

- avaliação do ciclo de vida do produto;

- certificação ISO 14001 e OHSAS 18001;

- produção mais limpa;

- ecodesign, segundo o diretor de desenvolvimento de produtos da DDEP os requisitos ambientais tornaram-se uma das prioridades primárias da empresa, mesmo que acima dos benefícios econômicos;

- compra verde;

- reuso de água;

- desenvolvimento de matérias-primas alternativas, no qual são realizados esforços em parceria com seus fornecedores para a inclusão de requisitos ambientais, com o objetivo de mitigar as agressões ao meio ambiente.

Koplin, Seuring e Mesterharm (2007) citam em seu estudo que adotando uma postura proativa e, por meio de uma parceria com a Universidade de Oldenburg, a Volkswagen realizou uma pesquisa-ação para integrar questões de sustentabilidade na sua política e processo de compras (revisão da estrutura de compras e envolvimento dos fornecedores de primeira camada).

No processo de compras sustentável, destacou-se que o passo mais importante para implementar requisitos de sustentabilidade é deixar claro estes requisitos para os fornecedores no contrato. Uma solicitação realizada pela Volkswagen é que seus fornecedores repassem seus requisitos a seus fornecedores (fornecedores de $2^{\mathrm{a}}$ camada), difundindo, desta forma, os requisitos sustentáveis pelos integrantes da sua cadeia de suprimentos.

A Hyundai Motor Company (HMC) por meio de um conceito inovador no cenário da sustentabilidade está desenvolvendo uma ferramenta que tem como principal objetivo medir a pegada de carbono de suas operações e, com estas informações, poder gerenciar melhor os riscos associados às mudanças climáticas, 
incentivar os compradores a preferirem produtos menos agressivos ao meio ambiente e à sociedade, e, com isso, aumentar sua participação no mercado (LEE, 2011).

Segundo Lee (2011), quando um fabricante de automóveis decide informar seus consumidores sobre a pegada de carbono de um tipo de carro ou modelo, a empresa deve considerar, para esta informação, suas emissões diretas e indiretas. Para que uma empresa focal melhore o nível de emissões de carbono de seus produtos, a empresa não deve avaliar apenas as emissões de suas plantas, mas também as emissões geradas pelos processos de seus fornecedores. Para tanto, a HMC elaborou um manual, no qual estão definidas as emissões diretas como sendo as geradas em suas plantas e limitou as emissões indiretas aos seus fornecedores, excluindo, neste primeiro momento, os integrantes a jusante na cadeia de suprimentos (distribuidores, consumidores, descarte e reciclagem).

Com base nos valores obtidos, a HMC pode desenhar um grande mapa do processo de carbono da sua cadeia de suprimentos, calcular a pegada de carbono de cada modelo e gerenciar sua cadeia de suprimentos, disseminando práticas e tecnologias sustentáveis dentre seus fornecedores de forma a influenciar a disseminação do programa da pegada de carbono por toda a sua cadeia de suprimentos.

Santos e Vanalle (2010), em seu estudo sobre as principais práticas de sustentabilidade na cadeia de suprimentos da indústria automotiva, identificaram por meio de um estudo de caso, realizado em um fornecedor de primeira camada da Ford Motor Company, as seguintes práticas:

- substituição de matérias-primas perigosas por materiais menos agressivos ao meio ambiente e ao homem;

- substituiu peças metálicas (tampas de válvulas, transmissões, cárter, etc.) por plásticos recicláveis de baixo peso, com o objetivo de reduzir o peso dos automóveis e consequentemente o consumo de combustível;

- drástica redução (aproximadamente 95\%) da geração de resíduos do processo de injeção ao desenvolver o polímero politetrafluoretileno (PTFE) resistente até $300{ }^{\circ} \mathrm{C}$.

Além dessas práticas, a empresa fornecedora, citada anteriormente, também desenvolve projetos voltados para a área de biocombustíveis, buscando desenvolver novas tecnologias para vedação de motores de alta pressão de combustão e desenvolver produtos customizados para todos os combustíveis atualmente em testes no mundo, como o Etanol, o Flexfuel, o Biodiesel e o Diesel Sintético, entre outros. Existem fortes investimentos na área de combustíveis alternativos; por exemplo: a empresa desenvolve componentes para carros híbridos e movidos à célula de combustível e Metanol.

\section{Metodologia de pesquisa}

Para atingir os objetivos, foi realizada uma pesquisa de campo exploratório-descritiva, com amostra não aleatória e intencional. Como essa amostra não é probabilística, não é possível afirmar que é representativa de todas as empresas integrantes de cadeias de suprimentos da indústria automotiva brasileira. Entretanto, cabe destacar que a amostra inclui 20 das 73 empresas cadastradas no site do Sindipeças, localizadas na região metropolitana de São Paulo, representando uma amostragem de 27,4\% do total (SINDICATO..., 2013).

A escolha pela região metropolitana de São Paulo se deu pelo fato de esta região ser o berço da indústria automotiva brasileira, região na qual se instalaram as primeiras empresas montadoras de automóveis no Brasil, como General Motors (São Caetano do Sul), Ford, Mercedes-Benz e Volkswagen (São Bernardo do Campo) e, consequentemente, as diversas indústrias participantes das cadeias de suprimentos destas montadoras, sendo estas últimas o foco desta pesquisa (SANTOS; VANALLE, 2010).

\subsection{Instrumento para coleta de dados}

$\mathrm{O}$ instrumento utilizado para coleta de dados foi um questionário. Excluindo os campos de dados da empresa, os quais foram obtidos por questões abertas, priorizou-se o uso de perguntas fechadas, pelo fato de serem mais fáceis de tabular e por coletar boa quantidade de informações. As perguntas fechadas utilizaram uma escala de Likert de 5 pontos, em que 1 representa totalmente sem importância ou não é considerado pela empresa e 5 representa extremamente importante ou implementado com sucesso pela empresa.

As perguntas foram agrupadas e ordenadas em quatros partes, a saber:

Parte 1 - Dados da empresa (com 6 questões englobando: o nome da empresa; principais clientes; principais produtos; quantidade de fornecedores; nível de fornecimento em relação à montadora; certificações que possui e um campo para observações).

Parte 2 - Integração de práticas de gerenciamento da cadeia de suprimentos sustentável aplicadas na empresa, que buscou identificar quais são as práticas aplicadas pelas empresas ou sua relevância (a partir de uma tabela para ser assinalada com 24 itens subdivididos em 4 blocos, sendo gerenciamento interno, pressões externas, cooperação dos clientes para a inclusão dos requisitos ambientais e ecodesign).

Parte 3 - Práticas consideradas no processo de seleção e desenvolvimento de fornecedores da empresa, que buscou identificar quais práticas são requisitadas 
pelas empresas ou sua relevância durante o processo de seleção e desenvolvimento de seus fornecedores (a partir de uma tabela para ser assinalada com 16 itens subdivididos em 3 blocos, sendo compras verdes, cooperação dos fornecedores na inclusão dos requisitos ambientais e ecodesign).

Parte 4 - Práticas referentes aos desempenhos ambiental, econômico e operacional, consideradas no processo de seleção e desenvolvimento de fornecedores, que buscou identificar quais as práticas desenvolvidas pelos fornecedores mais valorizadas pelas empresas (a partir de uma tabela para ser assinalada com 29 itens, subdivididos em 3 blocos: desempenho ambiental, desempenho econômico e desempenho operacional).

\subsection{Metodologia aplicada para análise dos dados}

Todo questionário respondido foi analisado e tabulado em planilhas elaboradas nos aplicativos IBM $^{\circledR}$ SPSS $^{\circledR}$ Statistcs e Microsoft ${ }^{\circledR}$ Excel, seguindo-se a ordem de recebimento e identificando as empresas por números em ordem crescente, com o objetivo de se manter a confidencialidade.

A partir destes dados, foram realizadas as seguintes análises:

- Estatística descritiva para utilização dos resultados da amostra em análises das médias. Com as pontuações médias de cada prática, estas foram ordenadas por bloco de práticas do questionário em ordem decrescente de valores, obtendo, assim, uma ordenação das práticas mais valorizadas para as menos valorizadas. Feita a análise individual das práticas de cada parte do questionário, foi realizada uma análise geral em que foi possível obter as práticas de sustentabilidade ambientais mais valorizadas pelas empresas integrantes da cadeia de suprimentos automotiva.

- Coeficiente de confiabilidade (alfa de Cronbach) que representa uma estimativa da confiabilidade do questionário; foi calculado para todos os blocos de práticas sustentáveis do questionário, utilizando-se o aplicativo IBM ${ }^{\circledast}$ SPSS $^{\circledR}$ Statistcs.
- Testes de hipóteses, foram realizadas análises utilizando os métodos do teste $\mathrm{Z}$ para média aritmética com desvio padrão conhecido, valor crítico e valor-p para testes de hipóteses.

Por meio do comando para análise de dados do aplicativo Microsoft ${ }^{\circledR}$ Excel, realizou-se o levantamento da estatística descritiva, para um coeficiente de confiança de $95 \%(\alpha=0,05)$.

Os cálculos para determinação dos coeficientes alfa de Cronbach foram realizados utilizando-se o aplicativo IBM ${ }^{\circledR}$ SPSS $^{\circledR}$ Statistcs, por meio do comando análise de confiabilidade. De acordo com Hair et al. (2009), o alfa de Cronbach é a medida de confiabilidade que varia de 0 a 1,0 e cujo limite de aceitabilidade inferior geralmente é de 0,70 , podendo ser diminuído para 0,60 para pesquisa exploratória.

Para os cálculos dos valores do teste $\mathrm{Z}$ e valor-p, utilizou-se o suplemento do Microsoft ${ }^{\circledR}$ Excel denominado PHStat2, específico para cálculos estatísticos e os valores críticos para o teste de hipóteses foram obtidos a partir da tabela de distribuição normal padronizada, utilizando-se como referência o nível de significância $(\alpha)$, que, por se trabalhar com um coeficiente de confiança 95\%, é igual a 0,05.

\section{Apresentação e discussão dos resultados}

Os resultados deste estudo foram obtidos com base nos 20 questionários respondidos dentre os 73 que foram enviados e estão representados nos quadros que integram este item do estudo.

\subsection{Características das empresas}

No Quadro 2, são apresentadas as características das empresas com relação ao seu nível de fornecimento junto às montadoras e também as normas de gestão que são certificadas.

Com relação ao nível de fornecimento às montadoras, dentre as empresas que responderam à pesquisa, $12(60 \%)$ são fornecedoras de primeira camada, 5 (25\%) são fornecedoras de segunda camada e $3(15 \%)$ são fornecedoras de terceira camada.

Tratando-se das certificações, as 20 (100\%) empresas possuem certificação ISO9001 ou ISO/ TS16949 referente ao sistema de gestão da qualidade,

Quadro 2. Características das empresas que responderam à pesquisa de campo.

\begin{tabular}{|c|c|c|c|c|c|}
\hline \multirow{4}{*}{$\begin{array}{c}\text { Características } \\
\text { das empresas }\end{array}$} & \multicolumn{2}{|c|}{ Nível de fornecimento } & $\mathbf{1}^{\text {a Camada }}$ & $\mathbf{2}^{\text {a Camada }}$ & $\mathbf{3}^{\text {a Camada }}$ \\
\cline { 2 - 6 } & \multicolumn{2}{|c|}{$\boldsymbol{\%}$} & 12 & 5 & 3 \\
\cline { 2 - 6 } & Certificações & $\begin{array}{c}\text { ISO 9001 ou } \\
\text { ISO/TS 16949 }\end{array}$ & ISO 14001 & OHSAS 18001 & SA 8000 \\
\cline { 2 - 6 } & Quantidade & 20 & 13 & 3 & 1 \\
\cline { 2 - 6 } & $\%$ & $100 \%$ & $65 \%$ & $15 \%$ & $5 \%$ \\
\hline
\end{tabular}


$13(65 \%)$ empresas possuem certificação ISO14001 referente ao sistema de gestão ambiental, 3 (15\%) empresas possuem certificação OHSAS 18001 referente ao sistema de gestão de saúde e segurança ocupacional e apenas $1(5 \%)$ empresa possui a certificação SA8000 referente à certificação que versa sobre responsabilidade social das empresas.

\subsection{Práticas de gerenciamento da cadeia de suprimentos sustentável}

O Quadro 3 apresenta os resultados encontrados com relação às práticas de gerenciamento da cadeia de suprimentos sustentável aplicadas nas empresas. Neste quadro, estão os valores encontrados para as práticas com as pontuações médias (obtidas a partir da análise estatística descritiva), os coeficientes de confiabilidade (alfa de Cronbach) para os blocos do questionário, os valores em que as hipóteses nulas foram aceitas, ou seja, que melhor representam as respostas das empresas, os valores do teste $\mathrm{Z}$ e os valores do teste Valor-p.

Com relação às práticas voltadas para o ecodesign, os resultados obtidos são semelhantes aos de Carter e Jennings (2000), que destacam dentre os principais critérios de sustentabilidade utilizados na seleção de fornecedores, o estabelecimento de lista de controle de substâncias perigosas. Práticas para evitar ou reduzir o uso de substâncias perigosas nos produtos e processo de produção também foram descritas por Bai e Sarkis (2010a) e Santos e Vanalle (2010). A prática de envolvimento dos fornecedores nas etapas de projeto e desenvolvimento de produtos também foi descrita no estudo de Koplin, Seuring e Mesterharm (2007) quando trata da inclusão da sustentabilidade na gestão da cadeia de suprimentos da Volkswagen.

A conformidade com a legislação ambiental foi é a prática reconhecida pelas empresas como a mais relevante entre as demais do bloco de práticas de gerenciamento interno, tal preocupação pode ser justificada com base no texto de Seuring et al. (2008) que citou os problemas que as empresas podem ter caso não cumpram a legislação, incluindo prejuízo à imagem e às suas vendas. Com relação às práticas voltadas para o monitoramento e redução da geração de resíduos, tais práticas também foram citadas por Rao e Holt (2005), Zhu, Sarkis e Lai (2007) e Bai e Sarkis (2010a).

Práticas relacionadas à cooperação dos clientes para a inclusão dos requisitos ambientais e pressões externas foram consideradas menos valorizadas pelas empresas, tendo atingido pontuação médias de 3,20 e 2,85 pontos, respectivamente. Fato este confirmado durante o teste da hipótese nula (Quadro 3), cujos resultados encontrados representam que as práticas relacionadas com o ecodesign e gerenciamento interno foram consideradas muito importantes, e as voltadas para cooperação dos clientes para a inclusão dos requisitos ambientais e pressões externas foram consideradas de alguma importância.

Ao analisar os resultados dos testes estatísticos (Quadro 3), percebe-se que os blocos de práticas voltadas ao ecodesign e gerenciamento interno, obtiveram 4 pontos para aceitação da hipótese nula, ou seja, são consideradas muito importantes pelas empresas, enquanto que os blocos, cujas práticas dizem respeito à cooperação dos clientes para a inclusão dos requisitos ambientais e pressões externas, obtiveram 3 pontos para aceitação da hipótese nula, sendo estas consideradas pelas empresas com um grau de importância menor, ou seja, de alguma importância, conforme escala de Likert adotada. Tais resultados são reforçados pelos resultados obtidos nos testes $\mathrm{Z}$ de hipóteses e o método do valor-p para o teste de hipóteses.

\subsection{Práticas de seleção e desenvolvimento de fornecedores}

O Quadro 4 apresenta os resultados encontrados com relação as práticas consideradas pelas empresas no processo de seleção e desenvolvimento de seus fornecedores. Neste quadro, estão os valores encontrados para as práticas com maiores pontuações médias (obtidas a partir da análise estatística descritiva), os coeficientes de confiabilidade (alfa de Cronbach) para os blocos do questionário, os valores em que as hipóteses nulas foram aceitas, ou seja, que melhor representam as respostas das empresas, os valores do teste $\mathrm{Z}$ e os valores do teste Valor-p.

Práticas que mantêm as empresas em conformidade com a legislação ambiental obtiveram pontuação média de 3,90 pontos, sendo consideradas pelas empresas de alguma importância a muito importantes, conforme escala de Likert. Tais práticas são citadas por Green, Morton e New (2000) e Sarkis (2003) em suas pesquisas quando citam o desenvolvimento de programas voltados para o cumprimento da legislação ambiental para o desenvolvimento de fornecedores sustentáveis. Adequações à legislação também são citadas por Bowen et al. (2001) em survey realizada com empresas públicas do Reino Unido, quando tratam das atividades inclusas na cadeia de suprimentos sustentáveis.

A certificação dos sistemas de gestão ambiental conforme a norma ISO 14001 obteve a pontuação média de 3,85 pontos, sendo considerada pelas empresas de alguma importância a muito importantes. Esta exigência foi observada na análise realizada por Zhu, Sarkis e Lai (2007), em que a montadora de motores chinesa DDEP obteve a certificação ISO 14001 incentivada por montadoras como Ford, GM e Toyota, além de outros clientes como IBM, Xerox e Brtistol-Myers, todos atuando em mercado global. 


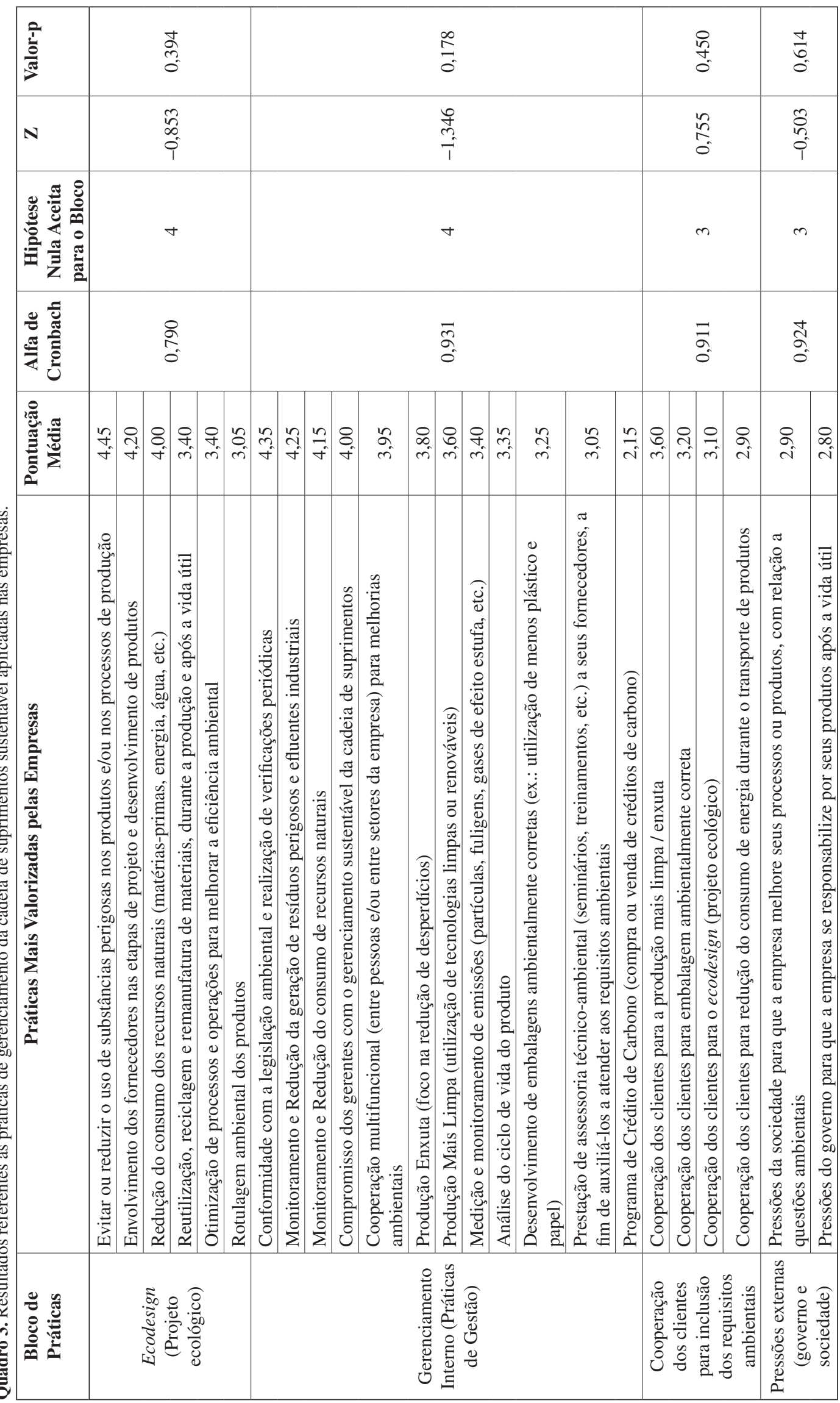


A certificação ambiental ISO 14001 passou a ser um pré-requisito no gerenciamento dos fornecedores sustentáveis da Volkswagen, conforme descrito por Koplin, Seuring e Mesterharm (2007) em sua pesquisa-ação sobre o envolvimento dos fornecedores para a inclusão da sustentabilidade em sua cadeia de suprimentos.

Dentre as práticas voltadas ao ecodesign de produtos por parte dos fornecedores, as práticas de sustentabilidade mais valorizadas são as dedicadas a evitar ou reduzir o uso de substâncias perigosas nos produtos e processos de produção, com uma pontuação média de 3,70 pontos, sendo consideradas de alguma importância a muito importantes, de acordo com a escala de Likert.

Isto mostra que as empresas preocupam-se em disseminar os conceitos de sustentabilidade em suas cadeias de suprimentos, conforme citado por Faustini e Alves (2009), pois, da mesma forma que esta pesquisa constatou a relevância das práticas de sustentabilidade voltadas para a eliminação ou redução do uso de substâncias perigosas nos produtos e processos de produção dentro das empresas, as mesmas empresas também consideram esta como uma prática importante para exigir de seus fornecedores uma vez que seus produtos serão agregados aos produtos das empresas.

As práticas de cooperação dos fornecedores para a produção mais limpa / enxuta são as mais valorizadas deste bloco pelas empresas, tendo obtido a pontuação média de 3,10 pontos. Bowen et al. (2001) e Zhu, Sarkis e Lai (2007) destacaram as práticas voltadas para a produção mais limpa em seus estudos, conforme citado anteriormente, durante análise das práticas relacionadas à cooperação dos clientes na inclusão dos requisitos ambientais.

Resumidamente, pode-se dizer que as práticas mais valorizadas no processo de seleção e desenvolvimento de seus fornecedores para as empresas da cadeia de suprimentos automotiva estudadas são as que envolvem a conformidade com a legislação ambiental, a certificação ISO 14001, evitar ou reduzir o uso de substâncias perigosas nos produtos e/ou processos de produção e a cooperação dos fornecedores para a produção mais limpa / enxuta.

Ao analisar os resultados dos testes estatísticos (Quadro 4), percebe-se que a hipótese nula aceita, para todos os blocos de práticas que dizem respeito às práticas consideradas pelas empresas no processo de seleção e desenvolvimento de seus fornecedores, foi de 3 pontos, ou seja, as empresas consideram tais práticas de alguma importância, conforme escala de Likert utilizada. Tais resultados são reforçados pelos resultados obtidos nos testes $\mathrm{Z}$ de hipóteses e o método do valor-p para o teste de hipóteses.

\subsection{Práticas de desempenho ambiental, econômico e operacional dos fornecedores}

O Quadro 5 apresenta os resultados encontrados com relação as práticas relacionadas aos desempenhos ambiental, econômico e operacional dos fornecedores. Neste quadro, estão os valores encontrados para as práticas com maiores pontuações médias (obtidas a partir da análise estatística descritiva), os coeficientes de confiabilidade (alfa de Cronbach) para os blocos do questionário, os valores em que as hipóteses nulas foram aceitas, ou seja, que melhor representam as respostas das empresas, os valores do teste $\mathrm{Z}$ e os valores do teste Valor-p.

Práticas relacionadas às entregas de produtos no prazo, compromisso com a gestão da qualidade, tempo de entrega e taxa de cumprimento de pedidos são as prática mais valorizadas no bloco que trata as práticas de desempenho operacional dos fornecedores. Tais pontos foram citados por Kuo, Wang e Tien (2010) em sua pesquisa sobre os métodos de seleção de fornecedores sustentáveis, quando apresentaram a estrutura com as seis dimensões: qualidade; custo; entrega; meio ambiente; responsabilidade social corporativa; e serviços. A quantidade de produtos entregues no prazo, o tempo de entrega e a taxa de cumprimento de pedidos fazem parte da dimensão denominada entrega, e o compromisso com a gestão da qualidade faz parte da dimensão qualidade.

No que diz respeito às práticas relacionadas ao desempenho econômico dos fornecedores, as práticas mais valorizadas são os custos com transporte dos produtos do fornecedor até a empresa e a consistência dos preços do fornecedor com a média do setor. Estes pontos também foram citados na pesquisa realizada por Kuo, Wang e Tien (2010), quando trata da dimensão custo para a seleção de fornecedores.

Tratando-se das práticas relacionadas ao desempenho ambiental dos fornecedores, as práticas mais valorizadas pelas empresas estão relacionadas à diminuição do consumo de materiais perigosos / prejudiciais / tóxicos, à redução da geração de águas residuais e à diminuição da frequência de acidentes ambientais, todas elas com a pontuação média de 3,70 pontos. Pode-se dizer que as práticas relacionadas à diminuição de materiais perigosos / prejudiciais / tóxicos, também foram citadas por Kuo, Wang e Tien (2010), quando trata da dimensão meio ambiente para seleção de fornecedores; em sua pesquisa os autores utilizaram a diretiva RoHS (restrição a substâncias perigosas) como requisito.

Ao analisar os resultados dos testes estatísticos (Quadro 5), verifica-se que todos os blocos de práticas tiveram a hipótese nula aceita com 4 pontos, ou seja, as empresas consideram como muito importantes as práticas voltadas para o desempenho ambiental, 


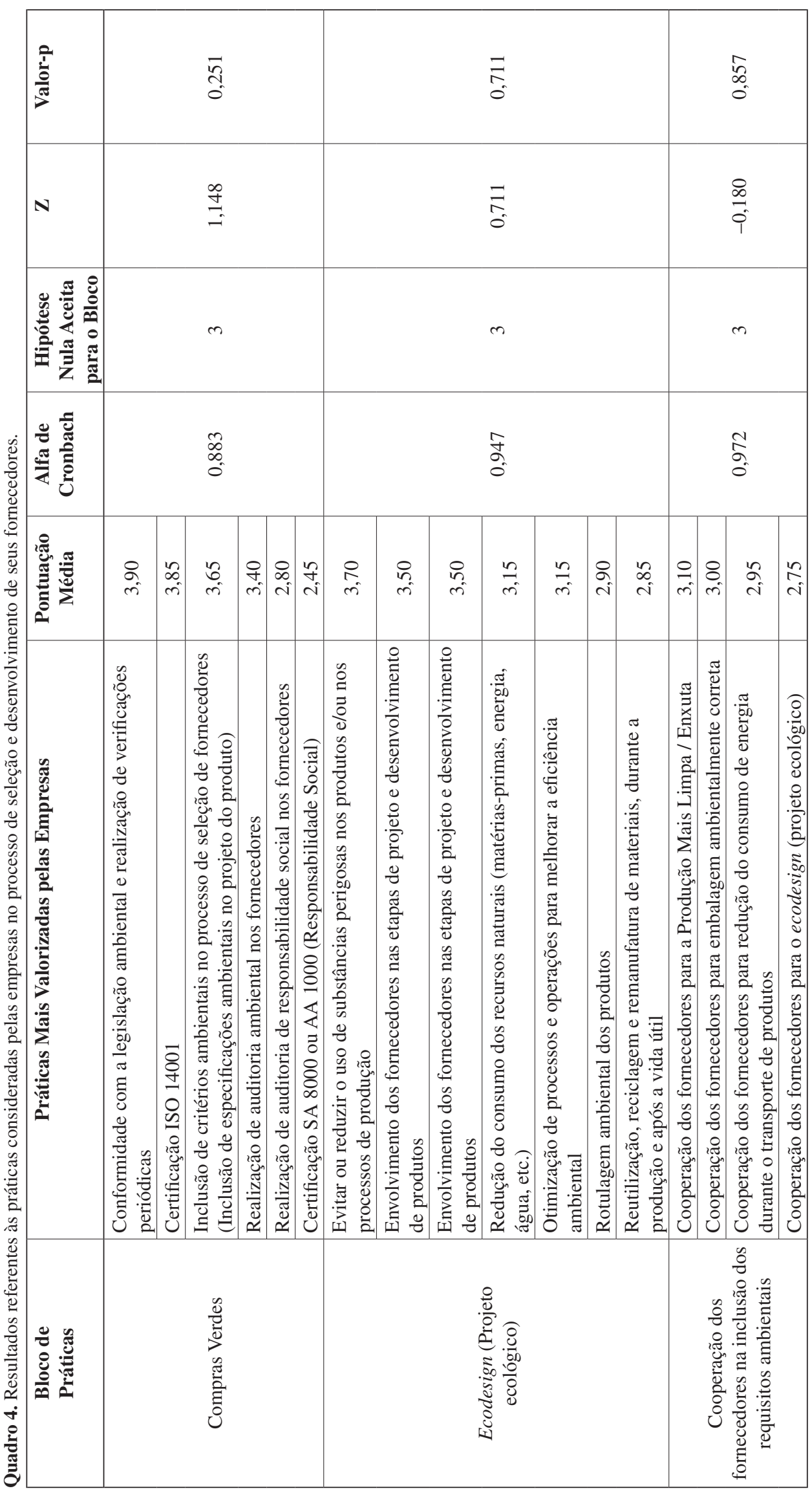




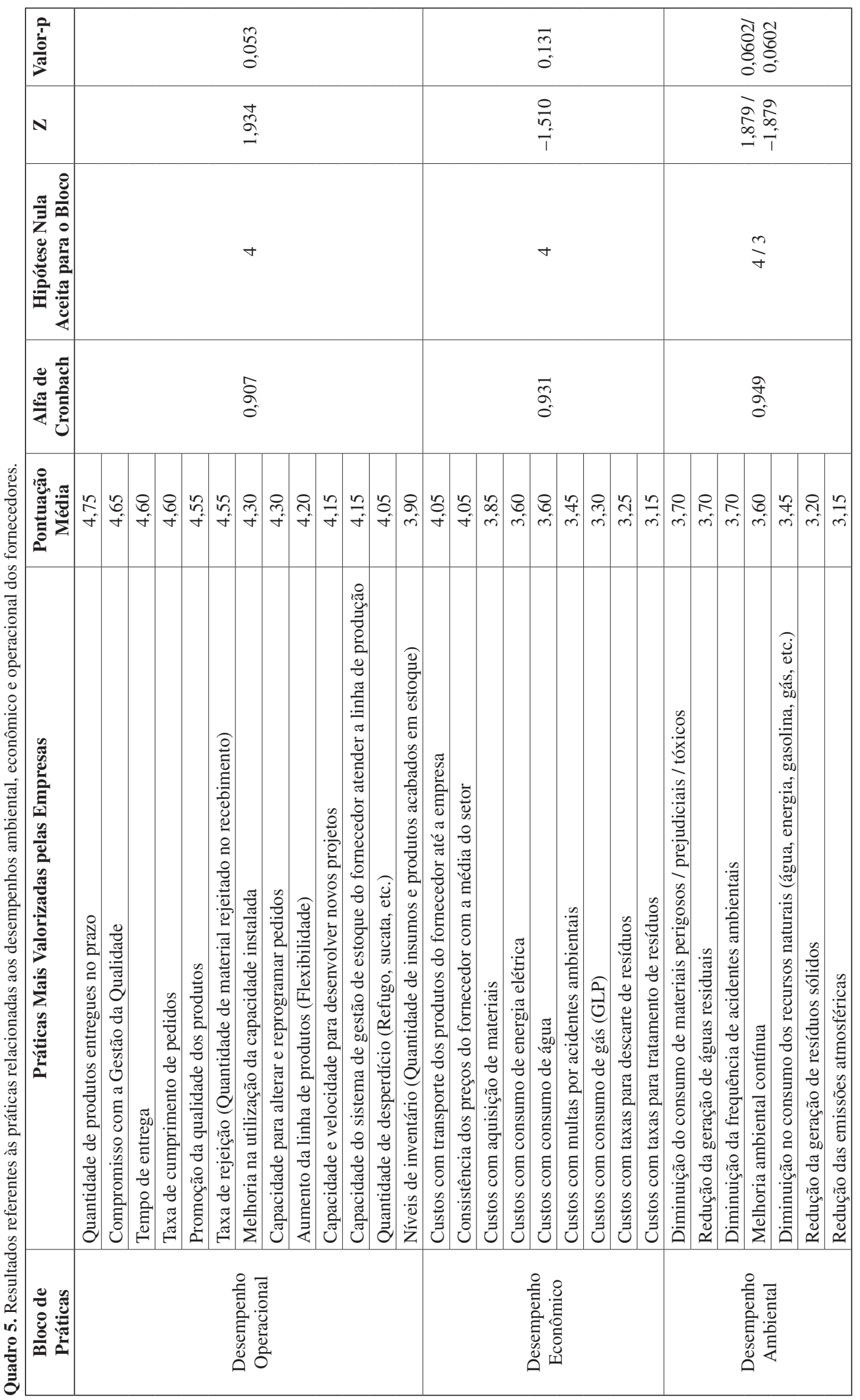


econômico e operacional, conforme escala de Likert utilizada. Entretanto verifica-se que as práticas relacionadas ao desempenho ambiental, também tiveram a hipótese nula aprovada com pontuação 3, que, conforme escala de Likert utilizada, equivale a alguma importância. A aceitação da hipótese nula em duas pontuações diferentes pode representar uma transição entre a relevância das práticas voltadas para o desempenho ambiental das empresas, porém não podemos afirmar que o nível de importância esteja aumentando ou diminuindo. Tais resultados são reforçados pelos resultados obtidos nos testes $\mathrm{Z}$ de hipóteses e o método do valor-p para o teste de hipóteses.

O Quadro 6 apresenta valores encontrados na pesquisa realizada nas empresas da cadeia de suprimentos do setor automotivo no Brasil, nos valores encontrados por Zhu, Sarkis e Lai (2007) em pesquisa realizada junto às empresas da cadeia de suprimentos do setor automotivo na China e por Ninlawan et al. (2010) em pesquisa realizada junto às empresas da cadeia de suprimentos do setor eletrônico na Î́ndia. Tais autores utilizaram, em suas pesquisas, questionários com blocos de questões semelhantes aos utilizados nesta pesquisa, que foi realizada em empresas integrantes da cadeia de suprimentos do setor automotivo no Brasil.

Comparando-se o resultado obtido nesta pesquisa para o bloco de práticas referentes ao desempenho ambiental (pontuação média de 3,50 pontos) com os resultados das pesquisas de Zhu, Sarkis e Lai (2007), aplicada em empresas da cadeia de suprimentos automotiva chinesa (pontuação média de 3,57 pontos), e de Ninlawan et al. (2010), aplicada na cadeia de suprimentos da indústria eletrônica indiana (pontuação média de 4,96 pontos), vê-se que as empresas localizadas na Índia valorizam mais as práticas voltadas para o desempenho ambiental que as demais, pois atingiram uma pontuação média acima dos 4 pontos, que equivale às práticas consideradas muito importantes.

Ao se comparar o resultado obtido nesta pesquisa para o bloco de práticas referentes ao desempenho econômico (pontuação média de 3,60 pontos) com os resultados das pesquisas de Zhu, Sarkis e Lai (2007), aplicada em empresas da cadeia de suprimentos automotiva chinesa (pontuação média de 3,32 pontos), e de Ninlawan et al. (2010), aplicada na cadeia de suprimentos da indústria eletrônica indiana (pontuação média de 3,97 pontos), vê-se que as empresas localizadas na Índia valorizam mais as práticas voltadas para o desempenho econômico que as demais, pois atingiram uma pontuação média próxima dos 4 pontos, que equivale às práticas consideradas muito importantes.

Comparando-se o resultado obtido nesta pesquisa para o bloco de práticas referentes ao desempenho operacional (pontuação média de 4,37 pontos) com os resultados das pesquisas de Zhu, Sarkis e Lai (2007), aplicada em empresas da cadeia de suprimentos automotiva chinesa (pontuação média de 3,58 pontos), pode-se dizer que as empresas integrantes da cadeia de suprimentos automotiva localizadas no Brasil valorizam mais as práticas que afetam o desempenho operacional do que as empresas da cadeia de suprimentos automotiva chinesa, pesquisadas por Zhu, Sarkis e Lai (2007).

\section{Considerações finais}

A questão principal que orientou o desenvolvimento desta pesquisa foi a necessidade de se compreender quais são as práticas de sustentabilidade mais valorizadas pelas empresas integrantes da cadeia de suprimentos automotiva.

Foram apresentados, de forma resumida, os conceitos sobre cadeia de suprimentos, cadeia de suprimentos sustentável, processo de seleção e desenvolvimento de fornecedores e processo de seleção e desenvolvimento de fornecedores sustentáveis. Foram apresentadas, também, as práticas sustentáveis que as empresas que participaram da pesquisa de campo estão valorizando em suas plantas e no processo de seleção e desenvolvimento de seus fornecedores, com o objetivo de tornar sua cadeia de suprimentos mais sustentável.

A metodologia quantitativa (baseada nos testes estatísticos), adotada nesta pesquisa de campo exploratório-descritiva, se mostrou adequada para responder ao objetivo, que consistiu em identificar e analisar as práticas de sustentabilidade mais valorizadas pelas empresas integrantes da cadeia de suprimentos do setor automotivo localizadas no Brasil,

Quadro 6. Pontuações médias obtidas para os blocos sobre desempenho ambiental, econômico e operacional nesta pesquisa e nas pesquisas dos autores Zhu, Sarkis e Lai (2007) e Ninlawan et al. (2010).

\begin{tabular}{|l|c|c|c|}
\hline \multicolumn{1}{|c|}{ Fatores / Práticas } & $\begin{array}{c}\text { Pontuação Média } \\
\text { Brasil }\end{array}$ & $\begin{array}{c}\text { Pontuação Média } \\
\text { China } \\
\text { Zhu, Sarkis e Lai (2007) }\end{array}$ & $\begin{array}{c}\text { Pontuação Média } \\
\text { Índia } \\
\text { Ninlawan et al. (2010) }\end{array}$ \\
\hline Desempenho Ambiental & 3,50 & 3,57 & 4,36 \\
\hline Desempenho Econômico & 3,60 & 3,32 & 3,97 \\
\hline Desempenho Operacional & 4,37 & 3,58 & $*$ \\
\hline
\end{tabular}

*Item não avaliado pelos autores durante a pesquisa. 
buscando contribuir com a literatura e direcionar novos estudos sobre o assunto.

Com os resultados da pesquisa, verificou-se que as práticas mais valorizadas pelas empresas integrantes da cadeia de suprimentos automotiva localizadas na região do ABC estão voltadas para a eliminação ou redução do uso de substâncias perigosas, visto que tais práticas são valorizadas internamente nas empresas e nas plantas de seus fornecedores, de forma a serem verificadas no processo de seleção e desenvolvimento de seus fornecedores e durante avaliação do desempenho ambiental destes fornecedores. Outra prática valorizada pelas empresas é o monitoramento e a redução da geração de resíduos perigosos e efluentes industriais. Tal tipo de prática, além de ter sua aplicação nas empresas valorizada, também é verificado durante avaliação do desempenho ambiental dos fornecedores.

$\mathrm{O}$ atendimento à legislação ambiental é uma das práticas que comprova que as empresas estão disseminando sua responsabilidade ambiental perante os integrantes das suas cadeias de suprimentos, como, também, preocupadas com suas próprias imagens perante a sociedade, pois, além de considerarem a conformidade com a legislação ambiental entre as práticas de sustentabilidade mais valorizadas em suas plantas, as empresas também estão considerando estas práticas no processo de seleção e desenvolvimento de seus fornecedores, tornando-se um requisito para fornecimento.

$\mathrm{O}$ envolvimento de fornecedores nas etapas de projeto, o monitoramento e a redução do consumo de recursos naturais e a cooperação dos clientes para a produção mais limpa / enxuta também são práticas valorizadas no gerenciamento interno das empresas. No processo de seleção e desenvolvimento de fornecedores, a certificação ISO 14001 e a cooperação dos fornecedores para a produção mais limpa / enxuta foram as práticas identificadas como as mais valorizadas pelas empresas.

Com relação aos desempenhos analisados, o desempenho operacional foi o mais valorizado pelas empresas, tendo se destacado as práticas relacionadas à quantidade de produtos entregues no prazo, o compromisso com a gestão da qualidade, o tempo de entrega e a taxa de cumprimento dos pedidos. Quanto ao desempenho econômico, as práticas mais valorizadas dizem respeito aos custos com transporte de produtos e à consistência dos preços com a média setorial. Por fim, tratando-se do desempenho ambiental, uma prática valorizada pelas empresas é a diminuição da frequência de acidentes ambientais.

Em face dos resultados, pode-se dizer que ainda são poucas as práticas de sustentabilidade que estão sendo valorizadas pelas empresas integrantes da cadeia de suprimentos do setor automotivo, sendo necessárias fortes mudanças, pois as empresas devem responder cada vez mais às exigências por parte de regulamentações do governo, cujo objetivo é a sustentabilidade e, conforme verificado na pesquisa, tais pressões são de pouca importância para as empresas integrantes da cadeia de suprimentos automotiva localizadas na região do $\mathrm{ABC}$, enquanto que, nas empresas da Índia (setor de eletrônicos) e China (setor automotivo), as pressões do governo já são consideradas muito importantes. Como estas mudanças requerem alterações nos produtos e processos produtivos, as grandes montadoras devem compartilhar sua necessidade com seus fornecedores, ou seja, difundir não apenas o conceito, mas a necessidade de mudanças em busca da sustentabilidade em toda a cadeia de suprimentos.

Tratando-se de uma pesquisa aplicada numa amostra local (região de São Paulo no Brasil), os resultados não podem ser generalizados para todas as empresas integrantes do setor automotivo, pois foi estudada apenas uma amostra de uma região das empresas integrantes do setor automotivo brasileiro.

Como sugestão para futuros estudos científicos, no âmbito de sustentabilidade nas indústrias automotivas, sugere-se que seja realizado um estudo dos requisitos sustentáveis definidos pelas montadoras para os fornecedores da sua cadeia de suprimentos e das ações dos fornecedores para o atendimento a estes requisitos. Investigar também, se estas exigências são diferentes das indústrias automobilísticas dos EUA ou da Europa.

\section{Agradecimentos}

Os autores agradecem o apoio recebido pela UNINOVE (Universidade Nove de Julho).

\section{Referências}

ASSOCIAÇÃO NACIONAL DOS FABRICANTES DE VEÍCULOS AUTOMOTORES - ANFAVEA. Anuário da Indústria Automobilística Brasileira. São Paulo, 2014. Disponível em: <http://www.anfavea. com.br>. Acesso em: 25 mar. 2014.

BAI, C.; SARKIS, J. Integrating sustainability into supplier selection with grey system and rough set methodologies. International Journal of Production Economics, v. 124, p. 252-264, 2010a. http://dx.doi.org/10.1016/j. ijpe.2009.11.023

BAI, C.; SARKIS, J. Green supplier development: analytical evaluation using rough set theory. Journal of Cleaner Production, v. 18, p. 1200-1210, 2010b. http://dx.doi. org/10.1016/j.jclepro.2010.01.016

BATT, P. J.; PURCHASE, S. Managing collaboration within networks and relationships. Industrial Marketing Management, v. 33, p.169-174, 2004. http://dx.doi. org/10.1016/j.indmarman.2003.11.004

BOWEN, F. E. et al. The role of supply management capabilities in green supply. Production and Operations Management, v. 10, p. 174-180, 2001. http://dx.doi. org/10.1111/j.1937-5956.2001.tb00077.x 
BURT, D.; DOYLE, M. The American Keiretsu: A Strategic Weapon for Global Competitiveness. Homewood: Business One Irwin, 1993.

CARTER, C. R.; JENNINGS, M. M. Purchasing's Contribution to the Socially Responsable Management of the Supply Chain. Center for Advanced Purchasing Studies, 2000

CHANG, B.; HUNG, H. A study of using RST to create the supplier selection model and decision-making rules. Expert Systems with Applications, v. 37, p. 82848295, 2010. http://dx.doi.org/10.1016/j.eswa.2010.05.056

COUNCIL OF SUPPLY CHAIN MANAGEMENT PROFESSIONALS - CSCMP. CSCMP Supply Chain Management Definitions. CSCMP, 2010. Disponível em: < http://cscmp.org/aboutcscmp/definitions.asp >. Acesso em: 24 abr. 2010.

DYER, J.; NOBEOKA, K. Creating and managing a highperformance knowledge-sharing network: the Toyota case. Strategic Management Journal, v. 21, n. 3, p. 345-67, 2000. http://dx.doi.org/10.1002/(SICI)10970266(200003)21:3\%3C345::AID-SMJ96\%3E3.0.CO;2-N

FAUSTINI, S.; ALVES, S. M. Gestão Sustentável da Cadeia de Suprimentos - Processos, Ações e Critérios Essenciais. In: SIMPÓSIO DE ENGENHARIA DE PRODUÇÃO, 16., 2009, Bauru. Anais... Bauru, 2009.

FREJ, T. A.; VIANA, J. C.; ALENCAR, L. H. Modelo de Seleção de Fornecedores com Apoio do Método Multicritério Promethee I. In: ENCONTRO NACIONAL DE ENGENHARIA DE PRODUÇÃO, 29., 2009, Salvador. Anais... Salvador, 2009.

GREEN JUNIOR, K. W. et al. Green supply chain management practices: impact on performance. Supply chain Management: An International Journal, v. 17, n. 3, 290-305, 2012.

GREEN, K.; MORTON, B.; NEW, S. Greening organizations. Organization \& Environment, v. 13, n. 2, p. 206-28, 2000. http://dx.doi. org/10.1177/1086026600132003

HANDFIELD, R. et al. Avoid the pitfalls in supply development. Sloan Management Review, v. 41, n. 2, p. 37, 2000.

HANDFIELD, R. B.; NICHOLS, E. L. Key issues in global supply base management. Industrial Marketing Management, v. 33, p. 29-35, 2004. http://dx.doi. org/10.1016/j.indmarman.2003.08.007

HAIR, J. F. et al. Análise multivariada de dados. 6. ed. Porto Alegre: Bookman, 2009.

HSU, C.; HU, A. H. Applying hazardous substance management to supplier selection using analytic network process. Journal of Cleaner Production, v. 17, p. 255-264, 2009. http://dx.doi.org/10.1016/j. jclepro.2008.05.004

JABBOUR, A. B. L. S.; JABBOUR, C. J. C. Are supplier selection criteria going Green? Case studies of companies in Brasil. Industrial Management \& Data Systems, v. 109, n. 4, p. 477-495, 2009. http://dx.doi. org/10.1108/02635570910948623

JABBOUR, A. B. L. S. et al. Esverdeando a cadeia de suprimentos: algumas evidências de empresas localizadas no Brasil. Revista Gestão e Prodição, v. 20, n. 4, p. 953-962, 2013.
KOPLIN, J.; SEURING, S.; MESTERHARM, M. Incorporating sustainability into supply management in the automotive industry - the case of the Wolkswagem AG. Journal of Clearner Production, v. 15, p. 1053-1062, 2007. http://dx.doi.org/10.1016/j. jclepro.2006.05.024

KRAJEWSKI, L. J.; RITSMAN, L. P.; MALHORTA, M. K. Administração de Produção e Operações. 8. ed. São Paulo: Pearson Prentice Hall, 2009.

KUO, R. J.; WANG, Y. C.; TIEN, F. C. Integration of artificial neural network and MADA methods for green supplier selection. Journal of Cleaner Production, v. 18, p. 1161-1170, 2010. http://dx.doi.org/10.1016/j. jclepro.2010.03.020

LAMBERT, D. M.; COOPER, M. C.; PAGH, J. D. Supply chain management: implementation issues and research opportunities. International Journal of Logistics Management, v. 9, n. 8, p. 1-19, 1998. http://dx.doi. org/10.1108/09574099810805807

LAMMING, R. Squaring lean supply with supply-chain management. International Journal of Operations and Production Management, v. 16, n. 2, p. 183-196, 1996. http://dx.doi.org/10.1108/01443579610109910

LEE, K. Integrating carbon footprint into supply chain management: the case of Hyundai Motor Company (HMC) in the automobile industry. Journal of Clearner Production, v. 19, p. 1216-1223, 2011. http://dx.doi. org/10.1016/j.jclepro.2011.03.010

LEITE, L. R.; SILVA, C. L. C.; MENEZES, E. A. Sustentabilidade: Um Diferencial Competitivo para Micro e Pequenas Empresas. In: ENCONTRO NACIONAL DE ENGENHARIA DE PRODUÇÃO, 29., 2009, Salvador. Anais... Salvador, 2009.

LINTON, J. D.; KLASSEN, R.; JAYARAMAN, V. Sustainable supply chains: An introduction. Journal of Operations Management, v. 25, p. 1075-1082, 2007. http://dx.doi.org/10.1016/j.jom.2007.01.012

MARTINS, P. G.; LAUGENI, F. P. Administração da produção. 2. ed. São Paulo: Saraiva, 2006.

NAWROCKA, D.; BRORSON, T.; LINDHQVIST, T. ISO 14001 in environmental supply chain practices. Journal of Cleaner Production, v. 17, p. 1435-1443, 2009. http://dx.doi.org/10.1016/j. jclepro.2009.05.004

NINLAWAN, C. et al. The implementation of Green Supply Chain Management Practices in Electronics Indsutry. In: INTERNATIONAL MULTICONFERENCE OF ENGINEERS AND COMPUTER SCIENTISTS, 2010, Hong Kong. Proceedings... Hong Kong, 2010.

ORSATO, R. J.; WELLS, P. The Automobile Industry \& Sustainability. Journal of Cleaner Production, v. 15, p. 989-993, 2007. http://dx.doi.org/10.1016/j. jclepro.2006.05.035

PAGELL, M.; ZHAOHUI, W. Building a more complete theory of sustainable supply chain management using case studies from 10 exemplars. Journal of Supply Chain Management, v. 45, p. 37-56, 2009. http:// dx.doi.org/10.1111/j.1745-493X.2009.03162.x

PAULA, C. S.; GONÇALVES, M. A.; COSCARELLI, B. V. O perfil de publicações sobre sustentabilidade nos eventos da Associação Nacional de Pós-graduação 
e Pesquisa em Administração. In: SIMPÓSIO DE ENGENHARIA DE PRODUÇÃO, 15., 2008, Bauru. Anais... Bauru, 2008.

POLIDÓRIO, G. R. S. O estágio de adoção das práticas de produção mais limpa na cadeia de suprimentos de artefatos de couro do oeste paulista. 2009. $132 \mathrm{f}$. Dissertação (Mestrado em Adminsitração de Empresas)Fundação Getúlio Vargas, São Paulo, 2009.

PORTER, M. E.; LINDE, V. C. Green and competitive: Ending the stalemate. Harvard Business Review, v. 73, n. 5, p. 120-134, 1995.

PUSAVEC, F.; KRAJNIK, P.; KOPAC, J. Transitioning to sustainable production - Part I: application on machining technologies. Journal of Cleaner Production, v. 18, p. 174-184, 2010. http://dx.doi.org/10.1016/j. jclepro.2009.08.010

RAO, P.; HOLT, D. Do green supply chains lead to competitiveness and economic performance? International Journal of Operations \& Production Management, v. 25, n. 9, 2005. http://dx.doi. org/10.1108/01443570510613956

RAZZOLINI, F. E.; RODRIGUEZ, C. M. T. Avaliação de fornecedores e processo de compras nos hospitais paranaenses: desafios para a competitividade. Tuiuti: Ciência e Cultura, v. 32-33, n. 4-5, p. 129-152, 2004.

ROSA, N. T. Definição de Planos de Ação para a Implantação da Gestão da Cadeia de Suprimentos entre uma Empresa de Médio Porte e seus Principais Fornecedores. 2004. 117 f. Dissertação (Mestrado em Engenharia)-Universidade Federal do Rio Grande do Sul, Porto Alegre, 2004.

SANTA-EULALIA, L. A. et al. An Essay on Green Supply Chain Design and Dynamic Alignment. In: INTERNATIONAL CONFERENCE ON INFORMATION SYSTEMS, LOGISTICS AND SUPPLY CHAIN, 3., 2010, Casablanca. Proceedings... Casablanca, 2010.

SANTOS, L. B.; VANALLE, R. M. Estudo das práticas de sustentabilidade na cadeia de suprimentos da indústria automobilística: Um estudo de caso. In: SIMPÓSIO DE ENGENHARIA DE PRODUÇÃO, 17., 2010, Bauru. Anais... Bauru, 2010.

SARKIS, J. A strategic decision framework for green supply chain management. Journal of Cleaner Production, v. 11, n. 4, p. 397-409, 2003. http://dx.doi.org/10.1016/ S0959-6526(02)00062-8

SCAVARDA, L. F. R.; HAMACHER, S. Evolução da Cadeia de Suprimentos da Indústria Automobilística no Brasil. Revista de Administração Contemporânea, v. 5, n. 2, p. 201-219, maio/ago, 2001.
SCANNELL, T.; VICKEY, S.; DROGE, C. Upstream supply chain management and competitive performance in the automotive supply industry. Journal of Business Logistics, v. 21, n. 1, p. 23-48, 2000.

SEMAN, N. A. A. et al. Green supply chain management: a review and research direction. International Journal of Managing Value and Supply Chain, v. 3, n. 1, p. 1-18, 2012. http://dx.doi.org/10.5121/ijmvsc.2012.3101

SEURING, S. et al. Sustainability and supply chain management - an introduction to special issue. Journal of Cleaner Production, v. 16, p. 1545-1551, 2008. http://dx.doi.org/10.1016/j.jclepro.2008.02.002

SILVA, J. E. Um modelo de programa de desenvolvimento de fornecedores em redes de empresas. 2004. Dissertação (Doutorado em Engenharia de Produção)-Universidade Federal de Santa Catarina, Florianópolis, 2004.

SINDICATO NACIONAL DA INDÚSTRIA DE COMPONENTES PARA VEÍCULOS AUTOMOTORES - SINDIPEÇAS. 2013. Disponível em: <http:// www.sindipecas.org.br>. Acesso em: 13 abr. 2013.

SRIVASTAVA, S. K. Green supply-chain management: A state-of-the-art literature review. International Journal of Management Reviews, v. 9, p. 53-80, 2007. http:// dx.doi.org/10.1111/j.1468-2370.2007.00202.x

VACHON, S.; KLASSEN, R. D. Extending green practices across the supply chain: The impact of upstream and downstream integration. International Journal of Operations \& Production Management, v. 26, n. 7, 2006. http://dx.doi.org/10.1108/01443570610672248

VELOSO, F. The automotive supply chain organization: global trends and perspectives. Cambridge, 2000.

ZHU, Q.; SARKIS, J.; LAI, K. Green supply-chain management: pressures, practices and performance within the Chinese automobile industry. Journal of Cleaner Production, v. 15, p. 1041-1052, 2007. http:// dx.doi.org/10.1016/j.jclepro.2006.05.021

ZHU, Q., SARKIS, J., LAI, K. Institutional-based antecedents and performance outcomes of internal and external Green supply chain management practices. Journal of purchasing \& Supply Management, v. 19, p. 106-117, 2013. http://dx.doi.org/10.1016/j. pursup.2012.12.001

ZUCATTO, L. C. Inovações em processos como uma forma de estruturar uma cadeia de suprimentos sustentável: são possíveis? In: ENCONTRO NACIONAL DE ENGENHARIA DE PRODUÇÃO, 28., 2008, Rio de Janeiro. Anais... Rio de Janeiro, 2008. 